Extended Abstract

\title{
Professional Social Network for Musicians: a New Technological Approach for Strengthening of Humanitarian Society
}

\author{
Marina Karaseva \\ The Moscow Tchaikovsky Conservatory, Department of Music Theory \\ Ph.D., Full professor, Advisor to the Rector / Bolshaya Nikitskaya street 13/6 125009 Moscow \\ Russian Federation \\ E-Mails: karaseva@mosconsv.ru, rectorat@mosconsv.ru
}

Tel.: +7-916-535-2575; Fax: +7-495-757-0629

Accepted:

\section{Introduction}

This paper is devoted to one of the important problems in the modern humanitarian society: to consolidation of musicians through the Internet and cultural connections while using the social networks. In my presentation the new software-based possibilities of such collaboration will be shown by the example of international social networking service for the musicians Splayn.com running by the Moscow Tchaikovsky Conservatory.

As we can see, the realm of Internet, which recently seemed to the most part of musicians as alien, soulless and hostile, nowadays becomes one of the essential components of our everyday life. The considerable increase of the social networks has been playing "first fiddle" in this process. Concurrently all the musicians (music performers and music theorists) begin to feel themselves even more public-oriented than other professional groups in the social networks because they need not to be so confidential in their occupation.

\section{Methods}

To disclose new tendencies, a sociological investigation based on the student's written interviews has been implemented in 2012 at the Moscow Conservatory under the scientific direction by prof. Marina Karaseva [1]. As provided by these interview results it was turned out that the most part of the respondents would like to find in the social networks not only services for communication and 
entertainments but also (and first of all) - services for professional self-presentation as well as for artistic self-promotion, e.g. for making their full creative portfolio.

Prof. Karaseva and the conservatory post-graduate student Sergei Uvarov have also examined all the existing Internet models of social networks for musicians [1]. The conclusions were as following: these networks are as usual: 1) not numerous, 2) local, 3) not oriented to classical academic music (but mainly to pop and rock music), 4) practically stagnant in its growth

\section{Results and Discussion}

In 2013 new social network for musician Splayn has been presented at the Moscow Conservatory (Site founder - S. Uvarov, co-founder and conservatory supervisor - M. Karaseva). Splayn [3] has some features which technologically distinguish it from other social networking services like facebook.com and vkontakte.ru. Splayn has been created by musicians, taking into account their professional and pedagogical needs. The new core concept of the delivery platform in Splayn contains, one might say, three driving principles: 1) engine for detecting the real authorship of music and video which are intended to upload on one's personal site page, 2) engine for the personal rating calculation, 3) site's open style: each internet user can enter Splayn without registration (at the same time he can do it if he wants to use the additional Splayn services). Thus, if the first principle decides to great extent the problem of restraint of the copyright piracy, the second one gives the possibility for each user to raise his rating.

In this connection, one should say some more words about the Splayn rating. Every Splayn user as well as every Splayn musical record has its own rating (calculated automatically in grades). This professional rating is very important for getting a way to the Splayn main page. Personal rating is formed by the amount of listening and downloading actions. The rating is also formed by comments and reviews of other users. A user rating is formed from the overall rating of his musical records (by now the site supports audio tracks in MP3 format and video tracks in MOV - iPhone, MP4, AVI, WMV, DivX and XviD) and their amounts, from a number of reviews which this user wrote and also from notes in his blog. So, the higher is user's rating the more well-known becomes the user for other Splayn-users. In the context of Splayn organization it is additionally important because even the young beginner in performing art, each musician from some distant region can get a lucky chance not to sink in the huge "Internet sea". Such a beginner can be noticed by music master, conservatory professor. Therefore, it may turn also a possibility for musician to be invited (as a player or composer) to the concert or festival at the Moscow conservatory or at some other famous cultural places.

\section{Conclusions}

All these Splayn features serve as real helpers for achieving geopolitical (as well as geo-cultural and popularizational) aims of spreading out good quality music (including classical, academic contemporary, folk and jazz) all over the world. Since the Splayn interface is bilingual (Russian and English), Splayn also have good opportunities for the successful international connections and collaborations between musicians and music lovers.

More program features of Splayn will be delivered in my presentation including its opportunities for music educational as well as presentational and pedagogical aspects (master classes, distant 
communications "professor - student"), and also its orientation to music organizations as a whole through the technologies of collective account on Splayn.

\section{References and Notes}

1. Karaseva, M.V.; Uvarov, S.A. Musician and Internet: about specificity of cognition of new technologies in the professional humanitarian society. Cultural and Political Aspects of American Studies. Russian State Humanitarian University. Moscow 2013, 308-318.

2. Karaseva M.V.; Amrachova A.A. Splayn as a new social network for musicians. Musiqi Duniasi 2013 4/57, 50-53.

3. http://www.splayn.com/

(C) 2015 by M.Karaseva; licensee MDPI and ISIS. This abstract is distributed under the terms and conditions of the Creative Commons Attribution license. 